\title{
Immediate effect of active release technique (ART) and dynamic soft tissue mobilization (DSTM) on hamstring tightness in young adults
}

\begin{abstract}
Background: Muscular flexibility is an important aspect of normal human function. Limited flexibility has been shown to predispose a person to several musculoskeletal overuse injuries and significantly affect a person's level of function. Muscular tightness is frequently postulated as an intrinsic risk factor for the development of a muscle injury. Lack of flexibility has been suggested as a predisposing factor to hamstring strains. The objective of our study was to find out the effect of Active Release Technique (ART) and Dynamic Soft Tissue Mobilization (DSTM) on hamstring tightness.
\end{abstract}

Procedure: The Ethical clearance was obtained for the study from Institutional Ethical Committee of Dr. A.P.J Abdul Kalam College of Physiotherapy Loni in January 2017. Written informed consent was obtained from all the subjects fitting in selection criteria. 30 normal healthy subjects (15 in each group) were recruited in the study under simple randomization method using sealed opaque envelopes. Group A received single session of ART Technique and Group B received single session of DSTM technique for hamstring tightness. Sit and reach flexibility tests were measured pre intervention and post intervention. Data was analyzed using t-test.

Result: The result shows that ART and DSTM increases immediate post-intervention hamstring flexibility within the group but there was no significant difference on comparison between two groups. However DSTM technique showed immediate relief in hamstring tightness pain and was more comfortable and effective for the patient as compared to ART.

Conclusion: The single intervention of ART and DSTM Technique is effective in improving Sit and reach flexibility measurements. But on comparison between ART \& DSTM technique there is no difference between sit and reach flexibility measurements.
Volume 3 Issue I - 2018

\author{
Sachin Maghade, Keerthi Rao \\ Physiotherapy Intern, India
}

Correspondence: Keerthi Rao, Professor, Dr APJ Abdul Kalam College of Physiotherapy, Loni, India, Email keerthimpt@gmail.com

Received: February 01, 2018 | Published: February 20, 2018

Keywords: hamstring tightness, active release technique, dynamic soft tissue mobilization

Abbreviations: ART, active release technique; DSTM, dynamic soft tissue mobilization; DDMT, dynamic deep muscle tissue

\section{Introduction}

Muscular flexibility is an important aspect of normal human function. Limited flexibility has been shown to predispose a person to several musculoskeletal overuse injuries and significantly affects a person's level of function. ${ }^{1}$ Muscular tightness is frequently postulated as an intrinsic risk factor for the development of a muscle injury. Lack of flexibility has been suggested as a predisposing factor for hamstring strains. ${ }^{2}$ Decreased hamstring flexibility is suggested to be one of the predisposing factors for hamstring strains and hamstring stretches are routinely used as part of a pre-exercise routine, usually after an aerobic warm-up. ${ }^{3}$ Proposed a theoretical model for hamstring strains, suggesting that they result from a complex interaction of four etiologic factors: warm-up, strength, fatigue, and flexibility. Reasons for stretching relate to beliefs that stretching exercises will increase flexibility and decrease muscle stiffness. Maintaining normal muscle length requires regular stretching to prevent muscle stiffness, decreases risk of musculoskeletal injuries and enhance physical performance. Maintaining the flexibility of hamstring muscle is important for general and athletic population and of utmost importance for health care professionals, to achieve this goal one needs to know the most effective and efficient technique to gain hamstring flexibility. ${ }^{1}$ Active release technique therapy for the hamstrings is designed to alleviate pain and tightness and help the hamstring to return to its normal condition. Active release technique has three unique objectives: Restoring free and unimpeded movement of soft tissue, the release of entrapped nerves, vasculature and lymphatic, and to re-establish optimal texture, resilience and function of soft tissues. Study has been done demonstrating that single session of Active release technique treatment is effective in a group of healthy, active male participants in improving hamstring flexibility. ${ }^{4}$ Dynamic soft tissue mobilizations Techniques which are commonly used by athletes to increase flexibility include static and ballistic stretching as well as Proprioceptive neuromuscular facilitation (Photo 1). It is widely believed amongst athletes, coaches, and therapists that massage is an effective treatment modality for increasing flexibility. ${ }^{5} \mathrm{~A}$ hierarchical dynamic deep muscle tissue model (DDMT) was developed to treat athletes with muscle tightness and associated soft tissue problems. ${ }^{6}$ This DDMT model consisted of a series of progressions from traditional to dynamic techniques which concentrated on one specific area of muscle tightness. It is hypothesized that incorporating active 
contractions into a massage protocol may increase muscle perfusion and decrease muscle stiffness. ${ }^{7}$ Clinical experience suggests that the DDMT model is an efficient, pain free intervention that appears to have an immediate effect on improving hamstring flexibility. However, at present, there is no scientific evidence to support this forms of intervention for muscle tightness problems. Furthermore, the current literature provides no information on the effectiveness of soft tissue techniques used in conjunction with dynamic functional techniques. Therefore, the purpose of this study was to determine the effect of dynamic STM on hamstring flexibility in healthy male subjects. Hence our study was to compare the active release technique versus dynamic soft tissue mobilization in hamstring tightness.

\section{Materials and methods}

The Ethical clearance was obtained for the study from Institutional Ethical Committee of Dr.A.P.J Abdul Kalam COPT Loni. Written informed consent was obtained from all the subject fitting the selection criteria. Initially the demographic data that is Name, Age, Gender, Height, Weight \& BMI were assessed. Subjects were randomly divided into two groups. i.e Experimental Group (ART) and Control Group (DSTM). Then the variable of the study that is sit and reach flexibility test was assessed before and immediately after the intervention for each subject \& score was noted down. ${ }^{9}$

\section{Sit and reach flexibility test}

This test involve sitting on the floor with legs stretched out straight ahead. ${ }^{10}$ Shoes should be removed. The soles of the feet are placed flat against the box. Both knees should be locked and pressed flat to the floor. With the palm facing downward, and the hands on top of each other, the subject reaches forward along the measuring line as far as possible. Ensure that the hands remain at the same level, not one reaching further forward than the other. After some practice reaches, the subject reaches out and holds that position for at one-two seconds while distance is recorded.

\section{Active release technique}

Group A- Subject received single session of ART on affected side. ${ }^{11}$ There are 3 steps to perform ART. Subject lies supine on the plinth and gentle tension was applied to the hamstring muscle along the entire length while stretching the leg in different positions to better work the muscle. Gentle tension was applied at the origin and insertion of the hamstring muscle. Gentle tension was applied around the adductors and gluteus muscle because hamstring connects to these muscles and that could be the source of hamstring tightness ${ }^{6}$ (Photo 2).

\section{Dynamic soft tissue mobilization}

Group B-Subject was positioned in prone and deep longitudinal strokes were applied to the entire hamstring muscle group to locate the specific area of hamstring muscle tightness. ${ }^{12}$ Once the specific area of was located, the remaining treatment was limited to this target area. After that the subject was positioned supine with the hip and knee flexed to ${ }^{13-15} 90$ degrees. Deep longitudinal strokes were applied in a distal to proximal direction to the area of hamstring tightness when the leg was passively extended. Then the next progressive, dynamic technique was applied. ${ }^{16-20}$ During this technique, the subject was required to actively extend their leg, in order to achieve reciprocal inhibition of the hamstrings. In this final procedure, the subject was instructed to contract the hamstring muscle group eccentrically against the resistance offered by the investigator's hand as the muscle is elongated up to the end range of motion. During this movement, five deep distal to proximal longitudinal strokes over the reduced hamstring area of muscle tightness are performed.

\section{Results}

(Table 1) shows that on Comparison of Pre and Post Sit to reach test values in ART group using paired t test $t$ value is 2.7662 and $p$ value $<0.0152$ it indicated statistically significant (Graph 1). (Table 2) shows that on Comparison of Pre and Post Sit to reach test values in DSTM group using paired test $t$ value is 14.4468 and $p$ value $<0.0001$ it indicated statistically significant (Graph 2). (Table 3) shows that on comparison of post value of sit and reach test after the ART and DSTM using unpaired t test $t$ value is 0.3793 and $p$ value is 0.7073 it indicated not statistically significant (Graph 3).

Table I Comparison of pre and post sit and reach test values in ART group

\begin{tabular}{llll}
\hline Group & $\begin{array}{l}\text { Mean } \pm \text { SD in } \\
\text { Cms }\end{array}$ & $\begin{array}{l}\text { T } \\
\text { value }\end{array}$ & P value \\
\hline $\begin{array}{l}\text { Pre } \\
\text { Intervention }\end{array}$ & $37.92 \pm 11.75$ & & $<0.0152$ \\
$\begin{array}{l}\text { Post } \\
\text { Intervention }\end{array}$ & $43.15 \pm 11.40$ & 2.7662 & $\begin{array}{l}\text { Extremely statistically } \\
\text { significant }\end{array}$ \\
\hline
\end{tabular}

Table 2 Comparison of pre and post sit to reach test values in DSTM group

\begin{tabular}{llll} 
Group & Mean \pm SD in Cms & T value & P value \\
\hline $\begin{array}{l}\text { Pre } \\
\text { Intervention }\end{array}$ & $38.3307 \pm 11.0208$ & & $<0.0001$ \\
$\begin{array}{l}\text { Post } \\
\text { Intervention }\end{array}$ & $44.6733 \pm 10.5280$ & 14.4468 & $\begin{array}{l}\text { Extremely } \\
\text { statistically } \\
\text { significant }\end{array}$
\end{tabular}

Table 3 Comparison of post value of sit and reach test after the ART and DSTM

\begin{tabular}{llll}
\hline Group & Mean \pm SD & $\begin{array}{l}\text { T } \\
\text { value }\end{array}$ & P value \\
\hline $\begin{array}{l}\text { Post intervention } \\
\text { (ART) }\end{array}$ & $43.1533 \pm 11.4048$ & & 0.7073 \\
$\begin{array}{l}\text { Post intervention } \\
\text { (DSTM) }\end{array}$ & $44.6733 \pm 10.5280$ & 0.3793 & $\begin{array}{l}\text { not statistically } \\
\text { significant }\end{array}$ \\
\hline
\end{tabular}

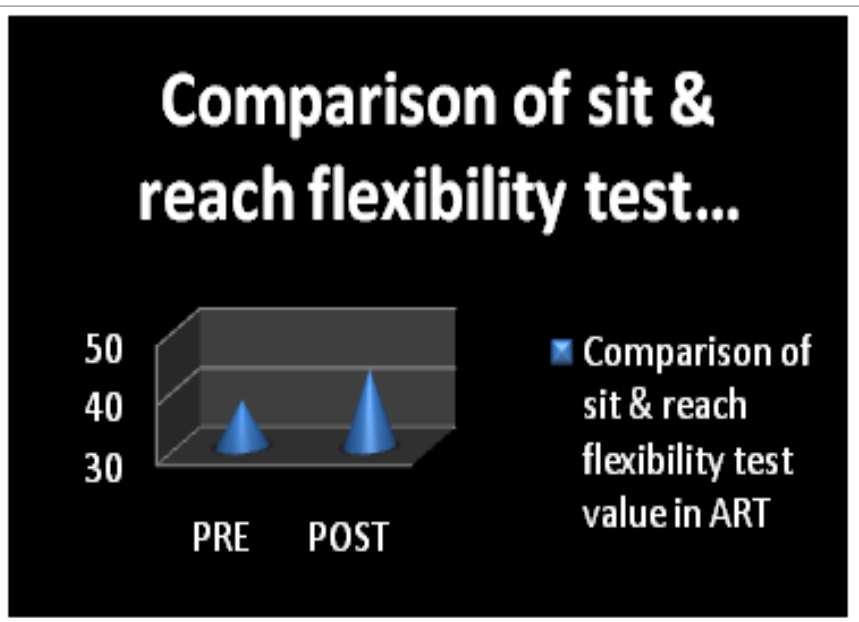

Graph I Comparison of pre and post Sit to reach test values in ART group in cms. 


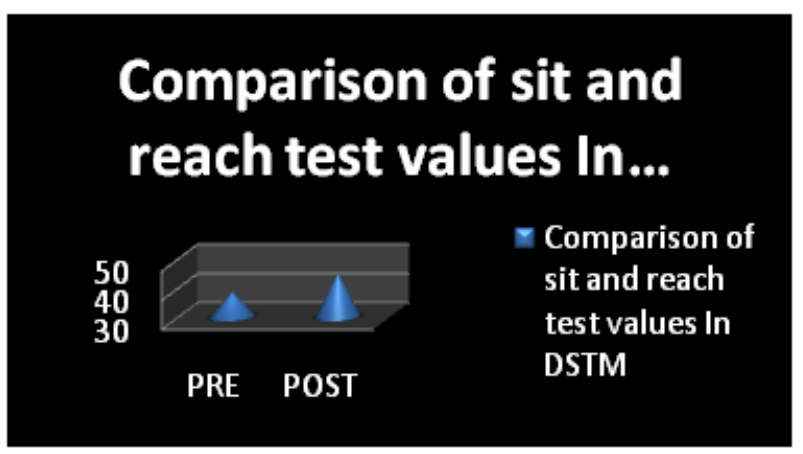

Graph 2 Comparison of pre and post Sit to reach test values in DSTM group in $\mathrm{cms}$.

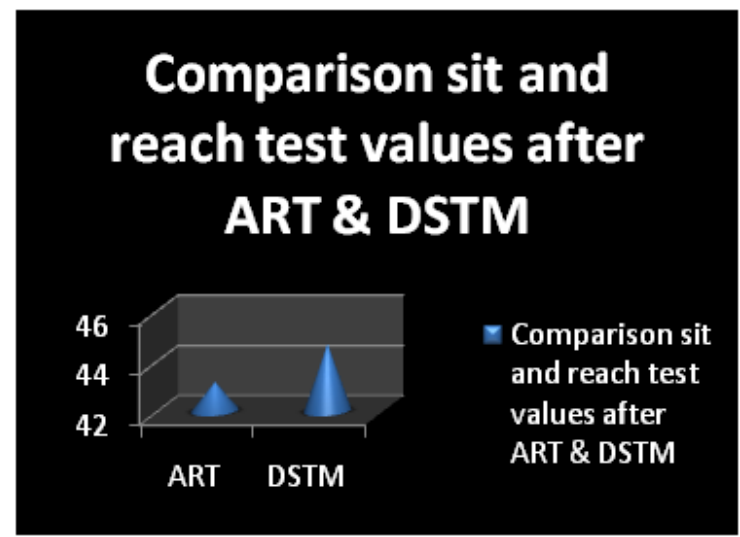

Graph 3 Comparison of post value of sit and reach test after the ART and self DSTM.

\section{Discussion}

The result of the present study demonstrated that ART and DSTM increases immediate post-intervention hamstring flexibility within the group but there was no significant difference on comparison between two groups. As per our knowledge this study was the first which compared the DSTM and Active release technique in healthy subjects with hamstring tightness with the single intervention. Active release technique and Dynamic soft tissue mobilization technique releases the scar tissue adhesions to allow full lengthening of the muscle and to regain flexibility for functional use. The present study compared the effectiveness of Active release technique \& Dynamic soft tissue mobilization on hamstring tightness, Even though ART produced a change of 2 to $3 \mathrm{cms}$ difference in pre and post test measures when observed within groups, a comparison between groups failed to produce significant differences which shows that ART does not have any clinical advantage than DSTM in improving hamstring flexibility. Result of our study are supported by Oves Patni et al which concluded that the ART produced a change of 4 and $5.2 \mathrm{cms}$ difference in pre and post test measures when observed within groups, a comparison between groups failed to produce significant differences which shows that ART does not have any clinical advantage than passive stretching in improving hamstring flexibility. ${ }^{20}$ It is concluded that after a single intervention Active release technique, immediate improvement was not observed but the technique was effective in improving the range of SLR after 24 hours. They also added that ART technique was no better than placebo. However, it is unlikely that this is the main treatment benefit; in a comparable LBP sample with SLR limitation, only one third of the subjects had signs of sensitized neural tissue. Another beneficial effect of the ART technique might be a change in stretch tolerance of the hamstrings. ${ }^{21}$ Goeken and Hof demonstrated that the increased range of SLR, following stretching, is mediated via an increase in hip flexion and hamstring length, and not related to increased hamstring viscoelastic properties. ${ }^{23}$ From our study we conclude that the DSTM produced a change of 5 and $5.2 \mathrm{cms}$ difference in pre and post sit and reach test measures when observed within groups, a comparison between groups failed to produce significant differences which shows that DSTM does not have any clinical advantage than ART in improving hamstring flexibility. Previous studies concluded that there was a significant increase in knee joint ROM at 2 min post-(12.7\%), Foam rolling for two minutes increased knee joint ROM by approximately $11^{\circ}$ and $9^{\circ}$ at 2 and 10 minutes, respectively. ${ }^{22}$ In Dynamic Soft Tissue Mobilization, it is hypothesized that incorporating active contraction into amassage protocol may increase muscle perfusion and decrease muscle stiffness. ${ }^{18}$ Inthis study, it is proved that DSTM has an immediate, significant effect on hamstring length. This result is well supported by previous study on hamstring flexibility in a sample of 30 males, concluded that DSTM significantly increases hamstring flexibility in healthy male subjects when compared to control group and classic soft tissue mobilization group. They also demonstratedthat a significant increase in hamstring length could be achieved by identifying a specific area of hamstring tightness and targeting treatment to this area using dynamic techniques. ${ }^{16}$ DSTM may mechanically shear out these cross-links and breakdown scar tissue, remobilizing the fascia back to its gel-like state. Once the fascia is in a more gel-like state, soft-tissue compliance increases allowing for greater range of motion.

\section{Conclusion}

We conclude that single intervention of Active release technique and Dynamic soft tissue mobilization technique is effective in improving Sit and reach flexibility measurements. But on comparison between ART \& DSTM technique there is no difference between sit and reach flexibility measurements. Dynamic soft tissue mobilization technique delivers immediate relief for hamstring tightness pain and better effective for the patient compare to active release technique.

\section{Acknowledgements}

None.

\section{Conflict of Interest}

The author declares no conflict of interest.

\section{References}

1. Nagarwal AK, Zutshi K, Ram CS, et al. Improvement of hamstring flexibility: A comparison between two PNF stretching techniques. International journal of sports science and engineering. 2010;4(1):25-33.

2. Glen M, De Pino, William G, Webright, et al. Duration of maintained hamstring flexibility after cessation of an acute static stretching protocol. $J$ Athl Train. 2000;35(1):56-59.

3. Kieran O Sullivan, Elaine Murray, David Sainsbury. The effect of warmup, static stretching and dynamic stretching on hamstring flexibility in previously injured subjects. BMC Musculoskeletal Disorder. 2009;10:137. 
4. Vijay Kage, Rakhi Ratnam. Immediate effect of active release technique versus mulligan bent leg raise in subject with hamstring tightness: A randomized clinical trial. Int J Physiother Res. 2014;2(1):301-304.

5. Hopperc S, Deacon S, Das, et al. Dynamic soft tissue mobilisation increases hamstring flexibility in healthy male subjects. Br J Sports Med. 2005;39(9):594-598

6. Hopper D. A new dynamic deep muscle tissue model (DDMT). Proceedings of the annual scientific conference in sports medicine, Canberra, Australia: ACT; 1991.

7. Hunter G. Specific soft tissue mobilization in the management of sof tissue dysfunction. Man Ther. 1998;3(1):2-11.

8. Hui SS, Yuen PY. Validity of the modified sit-and-reach flexibility test: A comparison with other protocols. Med Sci Sports Exer. 2000;32(9):16551659.

9. Marques AP, Vasconcelos AAP, Cabral CMN, et al. Effect of frequency of static stretching on flexibility, hamstring tightness and electro-myographic activity. Braz J Med Bio Res. 2009;42(10):949-953.

10. Abdul rahim Zakaria, Ganeswara Rao, Melam, et al. Efficacy of PNF stretching techniques on hamstring tightness in young male adult population. World Journal of Medical Sciences. 2012;7(1):23-26.

11. Scott D Davis, Paul E, Ashby, et al. The effectiveness of 3 stretching techniques on hamstring flexibility using consistent stretching parameters. J Strength Cond Res. 2005;19(1):27-32.

12. Nikos Malliaropoulos, Jurdan Mendiguchia, et al. Hamstring exercises fo track and field athletes: injury and exercise biomechanics, and possible implications for exercise selection and primary prevention. $\mathrm{Br} J$ Sports Med. 2012;46(12):846-851.

13. Corbin CB, Noble L. Flexibility A major component of physical fitness. $J$ Phys Educ Recreat Dance. 1980;51(6):57-60.
14. Prentice WE. Arnheim's Principles of Athletic Training. Madison, WI: McGraw-Hill; 2003. p. 85-90.

15. Brukner P, Khan K. Clinical sports medicine. 2nd ed. Roseville, NSW: UK: McGraw-Hill; 2001

16. Bandy W, Irion J, Briggler M. The effect of static and dynamic range of motion training on the flexibility of the hamstring muscles. J Orthop Sports Phys. 1998;27(4):295-300.

17. Herbert R, Gabriel M. Effects of stretching before and after exercising on muscle soreness and risk of injury: systematic review. BMJ. 2002;325(7362):468-478.

18. Shrier I. Stretching before exercise does not reduce the risk of local muscle injury: a critical review of the clinical and basic science literature. Clin J Sport Med. 1999;9(4):221-227.

19. Hemmings B. Physiological, psychological and performance effects of massage therapy in sport: a review of the literature. PhysTher Sport. 2001;2:165-170

20. Tiidus P. Manual massage and recovery of muscle function following exercise: A literature review. J Orthop Sports PhysTher. 19971;25(2):107112 .

21. Susan Hall. Basic of biomechanics. New York: University of Delaware; 2011. p.136-137.

22. Hunter G. Specific soft tissue mobilization in the management of soft tissue dysfunction. Man Ther. 1998;3(1):2-11.

23. Patterson P, Wiksten DL, Ray L, et al. The validity and reliability of the back saver sit-and-reach test in middle school girls and boys. Res $Q$ Exerc Sport. 1996;67(4):448-451. 